\title{
ICU Stay in Patients with Low Ejection Fraction Undergoing Cardiac Revascularization: Comparison of On-Pump Versus Off-Pump Coronary Artery Bypass Grafting
}

\author{
MUHAMMAD BILAL ${ }^{1}$, AHMAD FAWAD ${ }^{2}$, SYED MUMTAZ ANWAR SHAH ${ }^{3}$ \\ ${ }^{1}$ Senior Registrar, Adult Cardiac Surgery Department, Peshawar Institute of Cardiology, Peshawar \\ ${ }^{2}$ Associate Professor Cardiology North West General Hospital, Peshawar \\ ${ }^{3}$ Consultant Cardiac Surgeon, Fuji Foundation Hospital, Peshawar \\ Corresponding Author: Dr. Muhammad Bilal, Email: kmcite216@gmail.com, Cell No: +92 3339179792
}

\begin{abstract}
Background: Coronary artery bypass graft (CABG) surgery can result in serious complications for the patients. It is being currently performed with cardiopulmonary bypass with cardiac arrest in $80 \%$ of the cases across the world. There have debate in the past regarding the cardiac revascularization via CABG approaches.

Aim: The aim of this study is to study the difference in the patient's ICU stay who have low ejection fraction and are undergoing cardiac revascularization between off pump and on pump coronary artery bypass grafting.

Methodology: A sample size of 60 patients has been taken in the study with 30 patients' in the on-pump surgery group and 30 patients' in the off-pump surgery group. The data has been collected from department of Cardiac Srugery AFIC/NIHD, Rawalpindi.

Results and Conclusion: The study concludes that the on-pump CABG patients tend to have shorter ICU stay than the off-pump CABG patients who have low ejection fraction and are undergoing cardiac revascularization. Therefore, on-pump treatment is recommended in the study.

Keywords: Off pump, on pump, coronary artery bypass grafting, ICU stay, low ejection fraction, cardiac revascularization
\end{abstract}

\section{INTRODUCTION}

Coronary artery bypass graft (CABG) surgery can result in serious complications for the patients. It is being currently performed with cardiopulmonary bypass with cardiac arrest in $80 \%$ of the cases across the world. There tends to be a systematic inflammatory response of the cardiopulmonary bypass which usually takes place due to contact of extracorpeal circuit's artificial surfaces and circulating blood [1]. In order to avoid the systematic inflammation complications, in the 1990s the off-pump CABG was introduced again in the clinical practice.

There have debate in the past regarding the cardiac revascularization via $\mathrm{CABG}$ approaches.

Usually cardiopulmonary bypass is used in CABG. In this manner, the rate of mortality is greatly reduced i.e. it is $2 \%$ [2]. Off-pump CABG was developed in order to reduce the perioperative complications [3].

On the other hand, the ICU is the most expensive hospital area and the number of beds availability is also limited. Therefore, it is essential to identify the patients who require a long duration of ICU care. Moreover, in previous studies the factors that contribute to prolonged ICU stay after cardiac procedures have been identified but the impact of the prolonged stay in ICU after the discharge of patient has not been examined [4].

Various studies have identified that coronary artery bypass surgery has the ability to rescue a person who is having a heart attack, however, the benefit of bypass surgery in comparison with the medical therapy has not been found. Bypass surgery can result in loss of the mental function in the elderly [5]. The bypass surgery that does not make use of cardiopulmonary bypass is known as the offpump coronary artery bypass (OPCAB) [6]. OPCAB has been further refined and it has resulted in in minimally invasive direct coronary artery bypass surgery (MIDCAB).
In MIDICAB $5-10 \mathrm{~cm}$ incision is used for the bypass surgery. Moreover, there tend to be some complications associated with CABG which includes postperfusion syndrome [7], nonunion of the of the sternum, myocardial infarction, stroke, hemothorax etc. On the other hand, general surgical procedures have complications which include infections, keloid scarring, chronic pains, stress and even death.

There has been debate on the two approaches of cardiac revascularization via CABG which needs to be figured out. The aim of this study is to study the difference in the patient's ICU stay who have low ejection fraction and are undergoing cardiac revascularization between off pump and on pump coronary artery bypass grafting. The aim is also to identify the treatment option that is better for the patients.

The hypothesis of the study is: There is a difference between off pump and on pump coronary artery bypass grafting in term of ICU stay in patients with low ejection fraction undergoing cardiac revascularization.

\section{MATERIAL AND METHODS}

The study has been carried out by taking sample from the department of cardiac surgery, Peshawar Institute of Cardiology. The study was carried out over a period of 6 months starting from December 2020 to May 2021. A randomized control trial has been carried out in the study. The sample size has been calculated using the WHO calculator. The population mean of the patients' ICU stay who have low ejection rate (off-pump) $=8.73$ days [8]. The population mean for the on-pump patients' having low ejection fraction $=2.45$ [9]. The standard deviation of population is 0.17 , the power of test value is 80 percent, the confidence level is $95 \%$ and a sample size of 30 in 
each of the group has been taken into account which makes the total sample size of 60 .

Those patients' have been included in the sample who are aged between 40-80 of any gender. Moreover, those patients' have been considered who have an ejection fraction which is equal or less than $35 \%$ and are undergoing CABG. Those patients' have not been included in the study who have more than $35 \%$ of the ejection fraction or patients' that tend to have chronic kidney disease or sleep apnea or have history of the cardiac revascularization. Two groups of the patients were made i.e. on-pump CABG patients' (Group A) and off-pump CABG patients' (Group B). Analysis has been done using SPSS. T-test and chi square tests have been carried out in order to obtain suitable results.

\section{RESULTS}

The two groups means have been compared using independent sample t-test.

Table 1. Demographics of Group A and Group B

\begin{tabular}{|l|l|l|}
\hline AGE & GROUP A & GROUP B \\
\hline $40-60$ years & $10(33 \%)$ & $11(37 \%)$ \\
\hline $61-80$ years & $20(67 \%)$ & $19(63 \%)$ \\
\hline Total & $30(100 \%)$ & $30(100 \%)$ \\
\hline Mean and SD & 64 year \pm 12.77 & 66 year \pm 11.12 \\
\hline
\end{tabular}

Table 2. Characteristics of Group A and Group B

\begin{tabular}{|c|c|c|}
\hline \multicolumn{3}{|l|}{$\begin{array}{l}\text { BMI DISTRIBUTION } \\
P \text { value }=0.2298\end{array}$} \\
\hline & GROUP A & GROUP B \\
\hline$<25 \mathrm{Kg} / \mathrm{m}^{2}$ & $12(40 \%)$ & $13(43 \%)$ \\
\hline$>25 \mathrm{Kg} / \mathrm{m}^{2}$ & $18(60 \%)$ & $17(57 \%)$ \\
\hline Mean and SD & $26 \mathrm{Kg} / \mathrm{m}^{2} \pm 3.27$ & $27 \mathrm{Kg} / \mathrm{m}^{2} \pm 3.11$ \\
\hline \multicolumn{3}{|c|}{$\begin{array}{l}\text { VESSEL INVOLVEMENT } \\
P \text { value }=0.0010\end{array}$} \\
\hline$<2$ vessels & $11(37 \%)$ & $10(33 \%)$ \\
\hline$\geq 2$ vessels & $19(63 \%)$ & $20(67 \%)$ \\
\hline Mean and SD & $2 \pm 1.19$ & $3 \pm 1.04$ \\
\hline \multicolumn{3}{|l|}{$\begin{array}{l}\text { DIABETES } \\
\mathrm{P} \text { value }=0.7744\end{array}$} \\
\hline Diabetic & $21(70 \%)$ & $22(73 \%)$ \\
\hline Non diabetic & $9(30 \%)$ & $8(27 \%)$ \\
\hline \multicolumn{3}{|l|}{$\begin{array}{l}\text { HYPERTENSION } \\
\mathrm{P} \text { value }=0.7813\end{array}$} \\
\hline Hypertensive & $20(67 \%)$ & $21(70 \%)$ \\
\hline Non-Hypertensive & $10(33 \%)$ & $9(30 \%)$ \\
\hline \multicolumn{3}{|l|}{$\begin{array}{l}\text { ICU Stay } \\
P \text { value }=0.0126\end{array}$} \\
\hline Mean and SD & 3 days \pm 4.2 & 6 days \pm 4.8 \\
\hline \multicolumn{3}{|c|}{ STRATIFICATION OF MEAN ICU STAY W.R.T AGE DISTRIBUTION } \\
\hline $40-60$ years & 2 days \pm 3.82 & 5 days \pm 3.68 \\
\hline $61-80$ years & 3 days \pm 4.5 & 6 days \pm 5.02 \\
\hline \multicolumn{3}{|c|}{$\begin{array}{l}\text { STRATIFICATION OF MEAN ICU STAY W.R.T GENDER } \\
\text { DISTRIBUTION }\end{array}$} \\
\hline Male & 3 days \pm 4.12 & 6 days \pm 4.91 \\
\hline Female & 3 days \pm 4.37 & 6 days \pm 5.01 \\
\hline \multicolumn{3}{|c|}{ STRATIFICATION OF MEAN ICU STAY W.R.T BMI DISTRIBUTION } \\
\hline$<25 \mathrm{Kg} / \mathrm{m}^{2}$ & 3 days \pm 3.88 & 5 days \pm 4.57 \\
\hline$>25 \mathrm{Kg} / \mathrm{m}^{2}$ & 3 days \pm 4.97 & 6 days \pm 4.82 \\
\hline \multicolumn{3}{|c|}{$\begin{array}{l}\text { STRATIFICATION OF MEAN ICU STAY W.R.T VESSEL } \\
\text { INVOLVEMENT }\end{array}$} \\
\hline$<2$ vessels & 2 days \pm 3.79 & 5 days \pm 4.12 \\
\hline$\geq 2$ vessels & 3 days \pm 3.81 & 6 days \pm 4.77 \\
\hline \multicolumn{3}{|c|}{ STRATIFICATION OF MEAN ICU STAY W.R.T DIABETES MELLITUS } \\
\hline Diabetic & 3 days \pm 3.97 & 6 days \pm 5.04 \\
\hline Non diabetic & 2 days \pm 3.67 & 5 days \pm 4.10 \\
\hline \multicolumn{3}{|c|}{ STRATIFICATION OF MEAN ICU STAY W.R.T HYPERTENSION } \\
\hline Hypertensive & 3 days \pm 3.83 & 6 days \pm 4.99 \\
\hline Non-Hypertensive & 2 days \pm 3.48 & 5 days \pm 4.37 \\
\hline
\end{tabular}

The table indicates that in Group A there were 33\% of the respondents aged $40-60$ years, $67 \%$ respondents aged $61-80$ years and the mean was 64 . In group B, $37 \%$ of the respondents were aged $40-60$ years, $63 \%$ were aged $61-80$ years, and the mean was 66 .

The results reflect that in Group A, 40\% patients had BMI less than $25 \mathrm{~kg} / \mathrm{m}^{2}, 60 \%$ had BMI more than $25 \mathrm{~kg} / \mathrm{m}^{2}$. $37 \%$ of the patients had less than 2 vessels in vessel involvement whereas $63 \%$ had equal or more than 2 vessels in vessel involvement. In group A, $70 \%$ of patients were diabetic and $30 \%$ were non-diabetic, $67 \%$ were hyper tensive whereas $33 \%$ were non hyper tensive. More the mean ICU stay of Group A was 3 days. The mean was same for both males and females. The mean ICU stay of patients' aged 4-60 years was 2 days and for patients' aged 61-80 years was 3 days. The mean ICU stay of patients' who had less than 2 vessels was 2 days and the ones with equal or more than 2 was 3 days. The patients' who had BMI distribution less than $25 \mathrm{~kg} / \mathrm{m} 2$ had a mean ICU stay of 3 days and patients' who had BMI distribution more than 25 $\mathrm{kg} / \mathrm{m}^{2}$ had mean ICU stay 3 days. The ICU stay of diabetic was 3 days whereas of non-diabetic was 2 days. Lastly, the mean ICU stay of hypertensive patients was 3 days and non-hypertensive patients was 2 days.

The results reflect that $43 \%$ of the patients' in Group B had BMI distribution less than $25 \mathrm{~kg} / \mathrm{m}^{2}$ and $57 \%$ had BMI distribution more than $25 \mathrm{~kg} / \mathrm{m}^{2}$. 33\% of the patients had less than 2 vessels in vessel involvement and $67 \%$ had equal or more than 2 vessels in vessels involvement. In group B, $73 \%$ of patients were diabetic and $27 \%$ were nondiabetic, $70 \%$ were hyper tensive whereas $30 \%$ were non hyper tensive. Moreover, the mean ICU stay of Group B patients was 6 days. The mean was same for both males and females i.e. 6 days. Mean ICU stay of patients' aged 40-60 years was 5 days and patients' aged 61-80 days was 6 days. The mean ICU stay of patients' who had less than 2 vessels was 5 days and the ones with equal or more than 2 was 6 days. The patients' who had BMl distribution less than $25 \mathrm{~kg} / \mathrm{m}^{2}$ had a mean ICU stay of 5 days and patients' who had BMl distribution more than $25 \mathrm{~kg} / \mathrm{m}^{2}$ had mean ICU stay 6 days. The ICU stay of diabetic was 6 days whereas of non-diabetic was 5 days. Lastly, the mean ICU stay of hypertensive patients was 6 days and nonhypertensive patients was 5 days.

\section{DISCUSSION}

The study found the ICU stay is shorter in the on-pump CABG patients than the off-pump CABG patients who have low ejection fraction and are undergoing cardiac revascularization. There have been some agreements and disagreements of our results with the past studies. The results obtained in the current study are compared to the prior studies which includes that of Gupta et al [10] in which the mean ICU stay was found to be 8.73 days amongst the patients' who had low ejection fraction [off-pump]. For onpump coronary artery bypass grafting, Ahmedi [11] found the mean ICU stay to be 2.46 days in patients with low ejection fraction. The length of hospital stay for on-pump surgery patients' in the study of Paparella D et al [12] was found to be 12 days on average and the ICU length was 3.4 days. The same study also concluded that patients' 
undergoing OPCAB tend to have a stay in ICU shorter than the on-pump patients.

Wijeyesundera et al [13] compared the OPCAB with the on-pump CABG in their research study and the results showed that there was lesser myocardial damage with OPCAB. Cheng's [14] study compared the OPCAB with the conventional group of $C A B G$ and their results revealed that OPCAB group tends to have a shorter duration of ventilatory support as compared with the CABG group. [15] on the other hand carried out a comparison of the OPCAB group with the on-pump and concluded that there was increased risk of graft occlusion in the OPCAB group. Furthermore, the research study of Ercan et al [16] concluded that off-pump was not superior than the onpump surgery. The study also concluded that there were some advantages of off-pump over on-pump for a short term but the mid and long-term outcomes tend to be the same.

\section{CONCLUSION}

The study concludes that the on-pump CABG patients tend to have shorter ICU stay than the off-pump CABG patients who have low ejection fraction and are undergoing cardiac revascularization. For on-pump the mean ICU stay was 3 days whereas it was 6 days for off-pump patients. The results also that the results do not differ based on the gender as the mean ICU stay for both the genders was similar. The results reflected that patients with a higher age tend to stay in ICU for longer duration i.e. patients' in age group 61-80 years had longer stay than patients' in age group 40-60 years. The results show that BMI distribution does not impact the duration of stay of patients' in ICU in Group A but does have an impact on the off-pump patients. It is also concluded that patients with vessels less than 2 tend to have a lower mean ICU stay than the ones who have vessels equal or greater than two for both on-pump and off-pump patients. Moreover, diabetic patients tend to have longer ICU stay than the patients' who are nondiabetic for both on-pump and off-pump surgery. Lastly, patients' that are hypertensive has longer mean ICU stay than non-hypertensive patients for both on-pump and offpump. Therefore, based on the results, on-pump treatment is recommended in the study.

Limitations \& Recommendations: The study was carried out on a limited sample of 60 patients therefore the results cannot be generalized. The duration of study was limited to six months hence, the difference could not be studied for longer duration.

\section{REFERENCES}

1. Jongman RM, Zijlstra JG, Kok WF, van Harten $A E$, Mariani MA, Moser $J$, et al. Off-pump CABG surgery reduces systemic inflammation compared with on-pump surgery but does not change systemic endothelial responses: a prospective randomized study. Shock. 2014 Aug; 42(2):1218.
2. Takagi H, Umemoto T. Worse long-term survival after offpump than on-pump coronary artery bypass grafting. $J$ Thorac Cardiovasc Surg. 2014 Nov; 148(5):1820-9.

3. Shroyer AL, Hattler B, Wagner TH, Collins JF, Baltz $\mathrm{JH}$, Quin JA, et al. Five-Year Outcomes after On-Pump and Off-Pump Coronary-Artery Bypass. N Engl J Med. 2017 Aug 17; 377(7):623-632.

4. Mahesh B, Choong CK, Goldsmith K, Gerrard C, Nashef $\mathrm{SA}$, Vuylsteke A. Prolonged stay in intensive care unit is a powerful predictor of adverse outcomes after cardiac operations. Ann Thorac Surg. 2012 Jul; 94(1):109-16.

5. Bardakci H, Cheema FH, Topkara VK, Dang NC, Martens TP, Mercando ML. Discharge to home rates are significantly lower for octogenarians undergoing coronary artery bypass graft surgery. Ann Thorac Surg. 2007;83:483-9.

6. Toumpoulis IK, Anagnostopoulos CE, Chamogeorgakis TP Angouras DC. Impact of early and delayed stroke on inhospital and long-term mortality after isolated coronary artery bypass grafting. Am J Cardiol. 2008;102:411-7.

7. Gilman S. Cerebral disorders after open heart operations. N Engl J Med. 1965;272:489-98.

8. Gupta M, Mishra PK, Shoeb M, Agarwal A, Prasad J. A comparison of clinical outcomes of LVEF $\leq 35 \%$ versus LVEF $>35 \%$ in off-pump coronary artery bypass graft surgery. Int Surg J. 2017 Jun;4(6):1908-1912.

9. Seyed Hossein Ahmadi, Abbasali Karimi, Namvar Movahedi, Mahmood Shirzad, Is severely left ventricular dysfunction a predictor of early outcomes in patients with coronary artery bypass graft? Heart Asia 2010:62-66

10. Gupta M, Mishra PK, Shoeb M, Agarwal A, Prasad J. A comparison of clinical outcomes of LVEF $\leq 35 \%$ versus LVEF $>35 \%$ in off-pump coronary artery bypass graft surgery. Int Surg J. 2017 Jun;4(6):1908-1912.

11. Seyed Hossein Ahmadi, Abbasali Karimi, Namvar Movahedi, Mahmood Shirzad, Is severely left ventricular dysfunction a predictor of early outcomes in patients with coronary artery bypass graft? Heart Asia 2010:62-66.

12. Paparella D, Guida P, Scrascia G, Fanelli, V, Contini M, On-pump versus off-pump coronary artery bypass surgery in patients with preoperative anemia.

13. Wijeysundera DN, Beattie WS, Djaiani G, Rao V, Borger MA, Karkouti K, Cusimano RJ. Off-pump coronary artery surgery for reducing mortality and morbidity: meta-analysis of randomized and observational studies. J Am Coll Cardiol. 2005;9:872-882.

14. Cheng DC, Bainbridge D, Martin JE, Novick RJ. EvidenceBased Perioperative Clinical Outcomes Research Group. Does off-pump coronary artery bypass reduce mortality, morbidity, and resource utilization when compared with conventional coronary artery bypass? A meta-analysis of randomized trials. Anesthesiology. 2005;9:188-203.

15. Parolari A, Alamanni F, Polvani G, Agrifoglio M, Chen YB, Kassem S, Veglia F, Tremoli E, Biglioli P. Meta-analysis of randomized trials comparing off-pump with on-pump coronary artery bypass graft patency. Ann Thorac Surg. 2005;9:2121-2125.

16. Ercan, Abdulkadir et al. "A Comparison Of Off-Pump And On-Pump Coronary Bypass Surgery In Patients With Low Euroscore". Journal Of Cardiothoracic Surgery, vol 9, no. 1, 2014. Springer Science And Business Media LLC, doi:10.1186/1749-8090-9-105. Accessed 18 Oct 2020. 